\title{
A comparison of efficacy and safety with add on therapy of pioglitazone in adult patients of psoriasis with and without metabolic syndrome
}

\author{
Mahesh Chander Gupta ${ }^{1}$, Kartik Nayak ${ }^{1 *}$, Kamal Aggarwal $^{2}$
}

${ }^{1}$ Department of Pharmacology, ${ }^{2}$ Department of Dermatology, PGIMS, Rohtak, Haryana, India

\author{
Received: 27 March 2020 \\ Revised: 29 April 2020 \\ Accepted: 30 April 2020 \\ *Correspondence: \\ Dr. Kartik Nayak, \\ Email: kartik323033@gmail.com
}

Copyright: $@$ the author(s), publisher and licensee Medip Academy. This is an open-access article distributed under the terms of the Creative Commons Attribution Non-Commercial License, which permits unrestricted non-commercial use, distribution, and reproduction in any medium, provided the original work is properly cited.

\begin{abstract}
Background: Psoriasis is a chronic disease involving skin with systemic manifestations whose etiology remains unknown. In recent times, an increased occurrence of metabolic syndrome has been seen in psoriatic patients and potential role of antihyperglycemic in such conditions is being evaluated.

Methods: This was a prospective, controlled, randomized, open label comparative clinical study conducted on 51 psoriatic patients. The patients were divided into two groups with and without MS and both these groups were further randomised to receive either standard therapy alone (topical $0.05 \%$ betamethasone dipropionate applied twice daily) or therapy with pioglitazone $15 \mathrm{mg}$ orally once daily as add on to standard treatment. The study was conducted over a period of 12 weeks and the primary efficacy outcome was assessed by a change in psoriasis area severity index (PASI). The secondary outcomes were achievement PASI 50/75 and change in parameters of metabolic syndrome (MS). Change in quality of life assessed using dermatological life quality index (DLQI).

Results: Both the treatments significantly reduced the PASI score in psoriatic patients with and without MS, maximum being at 12 weeks. In patients with and without MS, pioglitazone caused a greater reduction in PASI score and DLQI score though it was found comparable to ST alone. Significant improvement in parameters of metabolic syndrome was observed in pioglitazone treated group.

Conclusions: Pioglitazone given as add on therapy caused an additional improvement in clinical severity and QOL in both the group of psoriatic patients with and without metabolic syndrome. Role of pioglitazone needs to be further explored with higher recommended dose range $(30 \mathrm{mg}$ and $45 \mathrm{mg}$ ) to demonstrate the usefulness of this drug in psoriatic patients.
\end{abstract}

Keywords: Psoriasis, Psoriasis area and severity index, Dermatology life quality index

\section{INTRODUCTION}

Psoriasis is a complex, chronic, multifactorial, systemic inflammatory disease that primarily involves skin with no clear cause or cure. It is a painful and debilating disease which affects people of all ages and in all countries making psoriasis a global problem, affecting millions of people worldwide. On the basis of age group, this disease has been classified into early onset psoriasis and late onset psoriasis. Early onset psoriasis also referred to as type I psoriasis has an onset before the age of 40 with a peak onset at 16-22 years of age and nearly comprises $70 \%$ of people living with psoriasis. Late onset psoriasis also known as type II psoriasis has an onset after the age of 40 years with a peak age of onset between 57-60 years. ${ }^{1}$ The exact aetiology of psoriasis is not known but this can be provoked by several intrinsic and extrinsic factors which include mild trauma, sunburns, systemic drugs and stress etc. ${ }^{2}$ Even though there is a suggestion 
that psoriasis could be an autoimmune disease, no autoantigen that is responsible for this disease has been found yet. ${ }^{3}$ In recent times, individuals with late onset psoriasis are also reported to be at an increased risk of developing serious co morbid illnesses and other noncommunicable diseases. The most common co morbid illnesses associated are cardiovascular diseases and metabolic syndrome. Even the individual parameters of metabolic syndrome also serve as an independent risk factors. ${ }^{4}$ The severity of these co morbid illnesses increases with age and recent studies have reported that type II psoriatic patients have statistically significant increase in chances of occurrence of hypertension, waist hip ratio, left ventricular hypertrophy, diabetes mellitus, deranged lipid profile etc. ${ }^{5}$

The treatment of psoriasis relies on the clinical severity of the disease and is primarily based on controlling the symptoms. Topical and systemic therapies along with phototherapy are the available options and in practice, a combination of these methods is often used. Treatment option selected is based on psoriasis severity at the time of presentation. Mild psoriasis is usually treated with topical therapy, progressing to phototherapy in the case of insufficient response. Moderate to severe psoriasis requires systemic therapy. ${ }^{6}$

Recently, a potential valuable role of anti-hyper glycaemic drugs has been demonstrated in inflammatory and proliferative disorders of skin such as psoriasis besides improving metabolic profile. The various classes of drugs include thiazolidinediones, biguanides, glucagon like peptide 1 agonist and dipeptidyl peptidase-4 inhibitors. ${ }^{7-10}$ Pioglitazone belonging to a class of thiazolidinediones group of drugs is a ligand for peroxisome proliferator-activated receptor- $\gamma$ (PPAR- $\gamma$ ) and has proven to decrease blood glucose and reduce severity of metabolic syndrome by enhancing insulin sensitivity. ${ }^{11}$ PPAR- $\gamma$ are expressed in human keratinocytes and treatment of these cultured human keratinocytes affected with psoriasis by thiazolidinediones has shown positive results by inhibiting keratinocyte proliferation and thereby reducing epidermal hyperplasia. These drugs also inhibit secretion of inflammatory cytokines primarily the IL-2 along with lowering of $\mathrm{C}$ reactive protein (CRP) levels and decreased recruitment of $\mathrm{CD} 4 \mathrm{~T}$ cells thereby demonstrating antiproliferative and anti-inflammatory properties in psoriasis. ${ }^{7}$ This drug is also well tolerated and does not possess the same immunosuppressive action as compared to the traditional anti-psoriatic medications.

A pilot trial was conducted by Shafiq et al, to compare pioglitazone versus placebo in patients with plaque psoriasis. ${ }^{12}$ It was 10 weeks randomized, double blinded, placebo controlled parallel group study enrolling 70 patients with moderate to severe psoriasis. The patients received one of the following treatments: pioglitazone $15 \mathrm{mg}$ or pioglitazone $30 \mathrm{mg}$ or placebo. Efficacy was assessed after 10 weeks of therapy by change in the PASI score. The clearance of psoriatic lesion was more than $40 \%$ in pioglitazone treated group as compared to $12.5 \%$ of those with placebo. The mean percentage reduction in PASI score in placebo, pioglitazone $15 \mathrm{mg}$ and pioglitazone $30 \mathrm{mg}$ groups were $21.6 \%, 41.1 \%$ and $47.5 \%$ respectively. No adverse drug reactions were detected in this study.

However, a double blinded randomized control trial conducted by Hafez et al, to evaluate the therapeutic efficacy of pioglitazone on psoriasis vulgaris and its comorbidities, did not reveal any significant improvement with pioglitazone. ${ }^{13}$ Forty eight patients with moderate to severe psoriasis were enrolled and were given oral pioglitazone $30 \mathrm{mg}$ daily for a period of 10 weeks. The treatment success was assessed in terms of PASI 75 as a primary outcome and changes in metabolic syndrome, insulin resistance and cardiovascular risk factors were considered as secondary outcome. Treatment success was achieved in $5 / 24 \quad(21 \%)$ in the pioglitazone group compared to $1 / 24(4 \%)$ in the placebo group; however, this difference was not significant and this short term (10 weeks duration) did not reveal any effect of pioglitazone $30 \mathrm{mg}$ on psoriatic disease

In view of such conflicting reports this study was carried out to evaluate the potential role of pioglitazone as add on to standard topical therapy in reducing the clinical severity and improving QoL of mild to moderate psoriatic disease in patients with and without metabolic syndrome.

\section{METHODS}

\section{Study design, population and treatments}

The study was a prospective, controlled, randomized, parallel group, open label, comparative clinical study conducted by Department of Pharmacology and Dermatology, Pt BD Sharma PGIMS, Rohtak, a tertiary care hospital in a state of Haryana from March 2018 to April 2019. The study was approved by the Institutional Ethics Committee of the institute.

Eighty fours patients with psoriasis were initially screened for clinical severity (mild-moderate) as per predefined inclusion and exclusion criteria. They were further screened for presence or absence of metabolic syndrome as per SAM-NCEP criteria. The study comprised of patients of either gender and was aged between 18-75 years with willingness to give informed consent for participation in the study. The patients suffered from chronic stable plaque psoriasis with mildmoderate clinical severity as determined by PASI score $(\leq 11)$. The study involved both group of patients either with or without metabolic syndrome. Metabolic syndrome was defined as presence of three or more criteria of south Asian modified national cholesterol education programme. ${ }^{14} \mathrm{HDL}$ cholesterol $<40 \mathrm{mg} / \mathrm{dl}$ $(1.03 \mathrm{mmol} / \mathrm{l})$ in men and $<50 \mathrm{mg} / \mathrm{dl}(1.29 \mathrm{mmol} / \mathrm{l})$ in 
women, fasting blood glucose $\geq 100 \mathrm{mg} / \mathrm{dl}(5.6 \mathrm{mmol} / \mathrm{l})$ or previously diagnosed with type 2 diabetes, blood pressure $\geq 130 / 85 \mathrm{mmHg}$ or on antihypertensive medication and central obesity (defined as waist circumference $\geq 90 \mathrm{~cm}$ in men and $80 \mathrm{~cm}$ in women according to the ethnic criteria for Asians), triglyceride $\geq 150 \mathrm{mg} / \mathrm{dl}(1.7 \mathrm{mmol} / \mathrm{l})$. Patients who have received systemic therapy in the past or were suffering from erythrodermic, generalized pustular psoriasis or an unstable form of plaque psoriasis of severe type were excluded from the study. Pregnant or lactating females at the time of study or patients who had a history of acute serious or psychiatric illnesses, chronic kidney/liver diseases or history of allergy to any of the study medications and not willing to give informed consent were also excluded from the study.

All the eligible patients were randomized into their respective study group by the simple randomisation technique. Patients of psoriasis without metabolic syndrome were randomized to receive either standard treatment (Group 1) or study treatment (Group 2) and with metabolic syndrome were also randomized in the similar way to receive standard treatment (Group 3) or Study treatment (Group 4). Standard treatment (ST) included topical $0.05 \%$ betamethasone dipropionate which was applied twice daily whereas study treatment included an oral therapy with tablet pioglitazone $15 \mathrm{mg}$ which was taken once daily in addition to ST. The treatment was given for a period of 12 weeks.

\section{Efficacy evaluation}

Efficacy assessment was done using primary and secondary end points. Primary end points were change in psoriasis area and severity index (PASI) score a dermatological life quality index (DLQI) score. Secondary end points were number of patients achieving PASI 50, 75 and change in parameters of metabolic syndrome.

\section{Primary end point}

\section{PASI score}

PASI score is a quantitative rating score that is used for measuring the severity of psoriatic lesions based on the area coverage and plaque appearance (erythema, scaling and induration). ${ }^{15}$ PASI combines the assessment of the severity of lesions and the area affected into a single score in the range 0 (no disease) to 72 (maximal disease). It is the current gold standard for assessment of severity of psoriasis. So, for the present study a PASI score of $\leq 11$ was considered to include the patients with mildmoderate severity of disease.

Efficacy assessment using PASI score was done before starting the treatment and then at the end of $4^{\text {th }}, 8^{\text {th }}$ and $12^{\text {th }}$ weeks post treatment and the mean change in PASI score was calculated at each visit.

\section{$D L Q I$}

DLQI was employed as a simple measure to assess the quality of life related to skin disease in psoriatic patients. ${ }^{16}$ It contained a series of 10 questions covering six domains regarding: symptoms and feelings, leisure, daily activity, work and school, personal relationship and treatment satisfaction. The response option ranges from 0 (not affected) to 3 (very much affected) thus giving an overall range from $0-30$, lower score meaning better quality of life. DLQI score was calculated before treatment and then at 12 weeks after the therapy. Efficacy was assessed by mean change in composite DLQI score.

\section{Secondary end points}

\section{Number of patients achieving PASI 50 and PASI 75}

PASI score is an important tool to define entry into a trial and it gives a measure of response to treatment that is important to define efficacy and outcomes. PASI 50 also called as clinically minimal response is said to happen when there is at least $50 \%$ improvement in disease from the baseline. PASI 75 also called as "Clinically meaningful success" is said to be happen when there is at least $75 \%$ improvement in disease from the baseline. After a follow up period of 12 weeks, number of patients achieving PASI 50 and PASI 75 was recorded.

\section{Metabolic syndrome}

The parameters of metabolic syndrome comprising of obesity, hypertension, triglycerides level, HDL level and fasting blood glucose level were assessed in all patients of psoriasis with metabolic syndrome. These were recorded at baseline followed by subsequent visits at $4^{\text {th }}$, $8^{\text {th }}$ and $12^{\text {th }}$ week to estimate the change in these parameters from baseline after 12 weeks of therapy.

\section{Statistical analysis}

The values of all continuous variables (e.g. PASI, DLQI scores in each group) were expressed as mean $\pm \mathrm{SE}$ of mean (SEM). Paired ' $t$ ' test was used to assess intragroup outcome comparison for changes within PASI score, DLQI score and individual parameters of metabolic syndrome at 12 weeks from baseline. Independent ' $t$ ' test was used for inter-group analysis between 2 groups at week 12 for comparing changes in PASI score, DLQI score and individual parameters of metabolic syndrome. $\mathrm{P}$ value of less than 0.05 was considered as statistically significant.

\section{RESULTS}

A total of 84 patients with symptoms of psoriasis were screened as per pre-defined inclusion and exclusion criteria. Out of these 26 patients did not fulfil inclusion criteria and 7 were not willing to sign the informed consent. Out of the 51 patients 24 patients had metabolic 
syndrome and remaining 27 were without metabolic syndrome. Distribution of patients in their respective groups is summarized in (Figure 1).

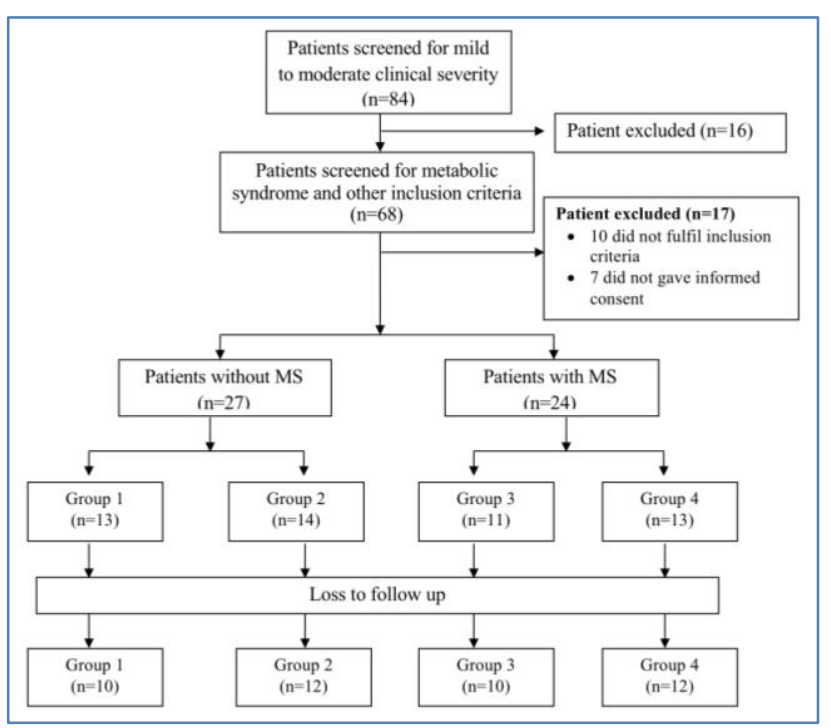

Figure 1: Flow chart for distribution of patients.

There was no significant difference in the baseline characteristics of control and study group patients with or without metabolic syndrome with respect to disease and metabolic syndrome (Table 1).

\section{PASI}

In patients of group 1 (without MS), receiving standard therapy alone, the baseline PASI score was $9.72 \pm 0.93$ which reduced to $8.65 \pm 0.82$ at week 4 (10.29\%; p value $0.003), 7.51 \pm 0.84$ at week $8(22.22 \%$; p value 0.001$)$ and $6.66 \pm 0.47$ at week 12 (29.74\%; p value 0.002$)$.
In group 2 patients (without MS) receiving pioglitazone as add on drug the baseline score was $9.4 \pm 0.45$ and there was a significant reduction in PASI score to $7.55 \pm 0.58$ at week 4 (20.59\%; p value 0.002$), 6.27 \pm 0.48$ at week 8 (33.77\%; p value 0.001 ) and $5.45 \pm 0.39$ at week 12 (42.21; p value 0.001) (Figure 2).

Above observations are indicative that standard therapy alone and add on therapy with pioglitazone produced significant and perpetual improvement in disease severity, maximum being at 12 weeks.

In patients of group 3 (with MS), receiving standard therapy alone, the baseline PASI score was $9.51 \pm 0.70$ which reduced to $8.63 \pm 0.69$ at week $4(9.89 \%$; p value $0.003), 7.75 \pm 0.64$ at week $8(18.86 \%$; p value 0.001$)$ and $6.67 \pm 0.44$ at week $12(29.05 \%$; p value 0.0001$)$. In group 4 patients (with MS) receiving pioglitazone as add on drug the baseline score was $9.6 \pm 0.53$ and there was a significant reduction in PASI score to $8.35 \pm 0.42$ at week 4 (12.20\%; p value 0.002), $7.05 \pm 0.36$ at week 8 (25.75\%; $\mathrm{p}$ value 0.001$)$ and $5.48 \pm 0.41$ at week 12 (42.41; p value 0.0001) (Figure 3).

The above observations indicate that there was a continuous and ongoing significant improvement in the clinical severity of psoriatic lesions with both the types of treatment (standard therapy alone and pioglitazone as add on treatment), maximum being at week 12 .

On intergroup comparison for reduction of PASI score in both groups of patients with and without metabolic syndrome, there was no significant difference between the standard therapy and pioglitazone as add on therapy. Although, pioglitazone was found to be clinically superior to standard therapy in reducing the PASI scores in these patients.

Table 1: Baseline characteristics of study population.

\begin{tabular}{|c|c|c|c|c|c|c|}
\hline \multirow{3}{*}{ Variables } & \multicolumn{3}{|c|}{ Patients without metabolic syndrome } & \multicolumn{3}{|c|}{ Patients with metabolic syndrome } \\
\hline & $\begin{array}{l}\text { Group } 1 \\
\text { ST }\end{array}$ & $\begin{array}{l}\text { Group } 2 \\
\text { pioglitazone } \\
\text { with ST }\end{array}$ & \multirow[t]{2}{*}{$P$ value } & $\begin{array}{l}\text { Group } 3 \\
\text { ST }\end{array}$ & $\begin{array}{l}\text { Group } 4 \\
\text { pioglitazone } \\
\text { with ST }\end{array}$ & \multirow[t]{2}{*}{$P$ value } \\
\hline & Mean \pm SEM & Mean \pm SEM & & Mean \pm SEM & Mean \pm SEM & \\
\hline Age (years) & $46.3 \pm 3.750$ & $46.91 \pm 3.117$ & NS & $53 \pm 2.80$ & $53.83 \pm 3.63$ & NS \\
\hline \multicolumn{7}{|l|}{ Gender } \\
\hline Male (N) & 7 & 11 & \multirow{2}{*}{ NS } & 9 & 10 & \multirow{2}{*}{ NS } \\
\hline Female $(\mathrm{N})$ & 3 & 1 & & 1 & 2 & \\
\hline PASI & $9.72 \pm 0.939$ & $9.4 \pm 0.45$ & NS & $9.51 \pm 0.703$ & $9.56 \pm 0.53$ & NS \\
\hline DLQI & $19.1 \pm 0.567$ & $18.25 \pm 0.66$ & NS & $18.6 \pm 0.54$ & $18.75 \pm 0.70$ & NS \\
\hline WC (cm) & $82.8 \pm 1.062$ & $83.91 \pm 1.46$ & NS & $97.6 \pm 1.32$ & $96.25 \pm 2.15$ & NS \\
\hline SBP (mm Hg) & $122.6 \pm 2.51$ & $123 \pm 1.16$ & NS & $152.8 \pm 2.99$ & $151.5 \pm 3.76$ & NS \\
\hline DBP (mm Hg) & $72 \pm 1.366$ & $77.33 \pm 1.33$ & NS & $92 \pm 1.66$ & $94.66 \pm 2.30$ & NS \\
\hline TG (mg/dl) & $115 \pm 8.511$ & $115.75 \pm 8.75$ & NS & $170.8 \pm 4.44$ & $168.33 \pm 5.79$ & NS \\
\hline HDL level (mg/dl) & $45.8 \pm 1.781$ & $47.33 \pm 2.46$ & NS & $37.8 \pm 0.67$ & $37.83 \pm 1.08$ & NS \\
\hline FBG (mg/dl) & $90 \pm 2.221$ & $92.91 \pm 2.01$ & NS & $117.1 \pm 11.23$ & $117.08 \pm 11.23$ & NS \\
\hline
\end{tabular}

NS- not significant. 


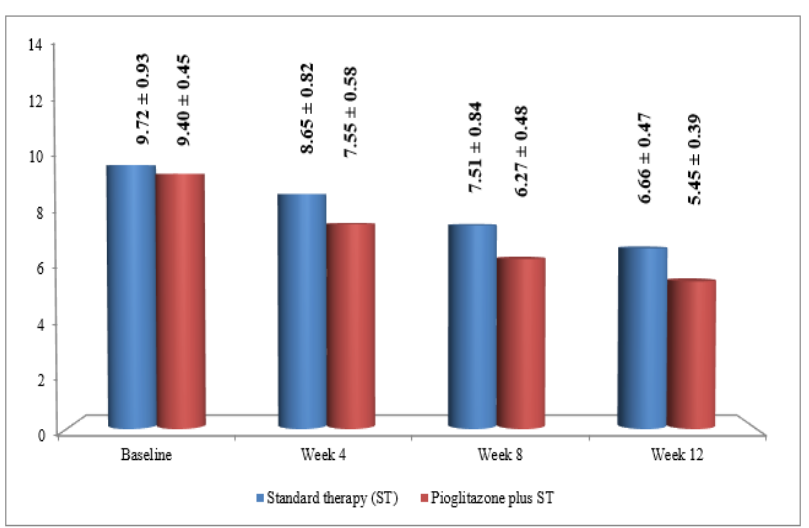

Figure 2: Comparison of changes in PASI with standard therapy alone and pioglitazone as add on therapy in patients of psoriasis without metabolic syndrome.

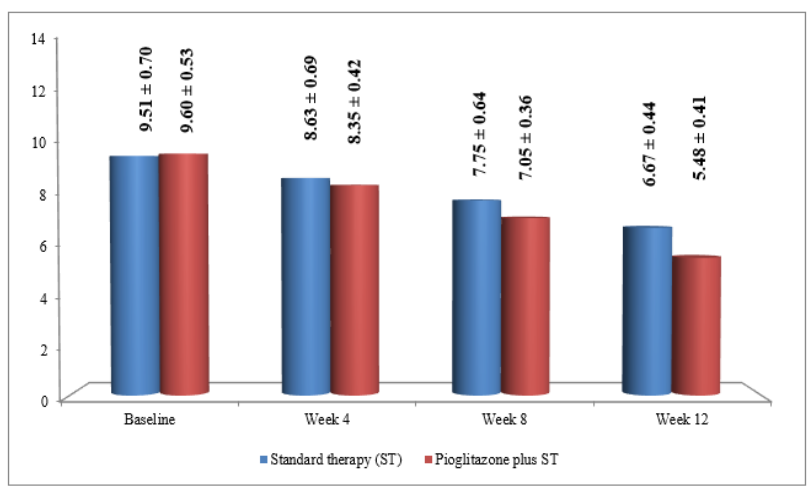

Figure 3: Comparison of changes in PASI with standard therapy alone and pioglitazone as add on therapy in patients of psoriasis with metabolic syndrome.

\section{Dermatological life quality index}

In patients of group 1(without MS), receiving standard therapy alone, the baseline DLQI score was $19.10 \pm 0.56$ which reduced to $14.20 \pm 0.57$ at week $12(25.62 \%$; p value 0.0001 ). In group 2 patients (without MS) receiving pioglitazone as add on drug the baseline score was $18.83 \pm 0.57$ and there was a significant reduction in DLQI score to $13.08 \pm 0.45$ at week $12(30.53 \%$; p value 0.0001$)$ (Table 2).

Above findings are indicative of the fact that there was a gradual improvement in QoL of psoriatic patients (without MS) with both the standard therapy alone and pioglitazone as add on drug.

In patients of group 3 (with MS), receiving standard therapy alone, the baseline DLQI score was $18.60 \pm 0.54$ which reduced to $14.30 \pm 0.61$ at week $12(23.11 \%$; p value 0.0001). In Group 4 patients (with MS) receiving pioglitazone as add on drug the baseline score was $18.75 \pm 0.70$ and there was a significant reduction in DLQI score to $13.00 \pm 0.66$ at week 12 (30.67\%; p value 0.0001$)$ (Table 2).

So, in patients of psoriasis with metabolic syndrome both the treatment types (standard therapy alone and pioglitazone as add on drug) were found to be significant in improving the QoL.

On intergroup comparison no significant difference was found between standard therapy alone and pioglitazone as add on drug in both the groups of patients with and without metabolic syndrome. Although, pioglitazone was found to be clinically superior to standard therapy in reducing the DLQI scores in these patients.

\section{PASI 50 and PASI 75}

Amongst the patients of psoriasis without metabolic syndrome, 4 patients achieved PASI 50 with pioglitazone as add on drug whereas none of the patient achieved PASI 50 with standard therapy alone.

None of the psoriatic patient with metabolic syndrome achieved PASI 75 with standard therapy alone or pioglitazone as add on drug.

Above observations shows greater improvement in PASI 50 with pioglitazone as add on drug in comparison to standard therapy alone and was equi-effective in both groups of patients with and without MS.

\section{Parameters of metabolic syndrome}

All the parameters of metabolic syndrome were significantly improved with pioglitazone as add on drug after 12 weeks of therapy. Pioglitazone was found to be significantly superior to standard therapy alone in improving these parameters except for fasting blood glucose (Table 3).

\section{Safety evaluation}

The most commonly reported adverse drug reactions with standard treatment alone were exacerbations and hypopigmentation in both the group of patients with and without MS. With pioglitazone as add on drug redness, exacerbation, edema, headache and vomiting were most common ADRs in patients without MS and abdominal pain, nausea and diarrhoea in patients with MS (Table 4).

The number of adverse events related to both the treatment types was found to be equivocal with mild severity. None of the patients discontinued the study medication due to any ADRs in any of the groups. Using WHO UMC scale, all the ADRs were evaluated for causality assessment and categorised as possible. ${ }^{17}$ 
Table 2: Comparison of composite dermatological life quality index (DLQI) in patients with and without metabolic syndrome.

\begin{tabular}{|c|c|c|c|c|}
\hline Variables & Time & $\begin{array}{l}\text { Standard treatment } \\
(0.05 \% \text { betamethasone } \\
\text { dipropionate) }\end{array}$ & $\begin{array}{l}\text { Pioglitazone with } \\
\text { standard treatment }\end{array}$ & P value (inter group) \\
\hline \multirow{4}{*}{ Without MS } & \multirow{2}{*}{ Baseline } & Mean \pm SEM (\%) & Mean \pm SEM (\%) & \\
\hline & & $19.10 \pm 0.56$ & $18.83 \pm 0.57$ & 0.665 \\
\hline & Week 12 & $14.20 \pm 0.57(25.62)$ & $13.08 \pm 0.45(30.53)$ & 0.136 \\
\hline & P value (intra group) & $<0.0001$ & $<0.0001$ & \\
\hline \multirow{3}{*}{ With MS } & Baseline & $18.60 \pm 0.54$ & $18.75 \pm 0.70$ & 0.986 \\
\hline & Week 12 & $14.30 \pm 0.61(23.11)$ & $13 \pm 0.66(30.67)$ & 0.190 \\
\hline & P value (intra group) & $<0.0001$ & $<0.0001$ & \\
\hline
\end{tabular}

Table 3: Changes in parameters of metabolic syndrome (in patients with MS).

\begin{tabular}{|c|c|c|c|c|c|}
\hline \multirow{2}{*}{$\begin{array}{l}\text { Treatment } \\
\text { Parameter }\end{array}$} & \multicolumn{2}{|c|}{$\begin{array}{l}\text { Group } 3 \\
\text { Standard treatment ( } 0.05 \% \\
\text { betamethasone dipropionate) }\end{array}$} & \multicolumn{2}{|c|}{$\begin{array}{l}\text { Group } 4 \\
\text { Pioglitazone as add on to } \\
\text { standard treatment }\end{array}$} & \multirow[t]{2}{*}{$\begin{array}{l}\text { P value (inter } \\
\text { group) }\end{array}$} \\
\hline & Mean change & P value ${ }^{a}$ & Mean change & P value ${ }^{a}$ & \\
\hline WC (cm) & $1.10 \pm 0.98$ & 0.29 & $-3.25 \pm 0.77$ & 0.002 & 0.002 \\
\hline SBP (mm Hg) & $-0.80 \pm 2.95$ & 1.0 & $-8.16 \pm 1.24$ & 0.001 & 0.024 \\
\hline $\mathrm{DBP}(\mathrm{mm} \mathrm{Hg})$ & $1 \pm 2.006$ & 1.0 & $-5.50 \pm 1.35$ & 0.010 & 0.012 \\
\hline TG (mg/dl) & $0.40 \pm 3.156$ & 1.0 & $-12.08 \pm 2.17$ & 0.001 & 0.003 \\
\hline HDL (mg/dl) & $0.90 \pm 1.46$ & 0.55 & $4.58 \pm 0.69$ & 0.001 & 0.007 \\
\hline FBG (mg/dl) & $-4.60 \pm 4.55$ & 1.0 & $-10.16 \pm 3.14$ & 0.008 & 0.314 \\
\hline
\end{tabular}

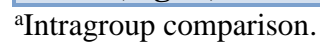

Table 4: Adverse drug reactions to standard treatment alone and pioglitazone treated patients.

\begin{tabular}{|lll|}
\hline Adverse event & Standard treatment alone $(\mathbf{n}=\mathbf{2 0})$ & Pioglitazone plus standard treatment $(\mathbf{n}=24)$ \\
\hline All adverse event & Number of patients $\mathbf{N}(\%)$ & \\
\hline Redness of patches & $7 / 20(35)$ & $8 / 24(33.33)$ \\
\hline Edema & $1 / 20(5)$ & $1 / 24(4.16)$ \\
\hline Hypopigmentation of skin & - & $1 / 24(4.16)$ \\
\hline Exacerbation of plaque & $4 / 20(10)$ & - \\
\hline Abdominal pain & - & $1 / 24(4.16)$ \\
\hline Headache & - & $1 / 24(4.16)$ \\
\hline Nausea & - & $1 / 24(4.16)$ \\
\hline Vomiting & - & $1 / 24(4.16)$ \\
\hline Diarrhoea & - & $1 / 24(4.16)$ \\
\hline
\end{tabular}

\section{DISCUSSION}

PASI score is the most common tool for the assessment of clinical severity of psoriatic disease and was used in the study as primary efficacy outcome. This was significantly improved with both standard therapies alone and with pioglitazone as add on drug in patients with and without MS. However, pioglitazone was found to be clinically superior to standard therapy alone in both the group of patients, though it failed to achieve statistical significance. These beneficial effects can be ascribed due to the fact that PPAR- $\gamma$ are expressed in human keratinocytes and treatment of these cultured human keratinocytes affected with psoriasis by thiazolidinediones has shown positive results by inhibiting keratinocyte proliferation and thereby reducing epidermal hyperplasia. These drugs also inhibit secretion of inflammatory cytokines primarily the IL-2 along with lowering of $\mathrm{C}$ reactive protein (CRP) levels and decreased recruitment of $\mathrm{CD} 4 \mathrm{~T}$ cells thereby demonstrating antiproliferative and anti-inflammatory properties in psoriasis. ${ }^{7}$ Vahide et al compared the efficacy and safety of a combination of methotrexate plus pioglitazone and methotrexate alone in plaque-type psoriasis. ${ }^{18}$ Patients were randomized into two groups receiving treatment with methotrexate alone (group A) or methotrexate plus pioglitazone (group B) for 16 weeks. After 16 weeks of therapy, there was significant 
percentage of reduction in the mean PASI score $70.3 \%$ in group B and $60.2 \%$ in group A. Therefore, it was concluded that pioglitazone enhances the therapeutic effect of methotrexate in plaque-type psoriasis. Mittal et al conducted a randomized, double-blinded, placebocontrolled clinical trial to study the efficacy and safety of combination acitretin and pioglitazone therapy in patients with moderate to severe chronic plaque-type psoriasis. ${ }^{19}$ After 12 weeks of therapy, the PASI score reduced was $64.2 \%$ in the acitretin plus pioglitazone group and $51.7 \%$ in the acitretin plus placebo group indicating that pioglitazone caused an additional improvement in reducing PASI score.

In the present study, standard therapy alone and pioglitazone as add on drug also caused a significant improvement in QoL, though both the therapies were found to be comparable. However, pioglitazone was found to be clinically superior to standard therapy alone. A study was conducted by Vahide et al to compare the efficacy of combination of methotrexate plus pioglitazone and methotrexate alone for improvement in QoL of psoriatic patients. ${ }^{18}$ After 16 weeks of therapy, there was greater reduction in mean DLQI score by pioglitazone treated group in comparison to standard group, but pioglitazone failed to achieve the statistical significant proportions. The number of patients achieving PASI 50 was significantly more in group receiving pioglitazone as add on drug and the benefit was observed both in patients with and without MS. In the similar study by Vahide et al fourteen patients $(63.6 \%)$ achieved PASI 75 in pioglitazone group (group B) as compared to two patients $(9.1 \%)$ in standard therapy alone (group A) group and the difference was significant statistically. ${ }^{18}$ Pioglitazone as add on therapy caused a significant improvement in all parameters of metabolic syndrome except for fasting blood glucose as compared to standard therapy alone. This probably could be due to blood glucose enhancement due to use of topical glucocorticoids

The add on therapy with pioglitazone caused a superior outcome with respect to PASI score as well as QoL though it did not achieve the statistical significance for the study. This could be attributed to usage of minimum dose of pioglitazone i.e., $15 \mathrm{mg}$ once daily and probably could be much more and significant with a dose of 30 $\mathrm{mg}$. Hence further more clinical trials are required with increased doses of pioglitazone ( $30 \mathrm{mg}$ and $45 \mathrm{mg}$ ) to establish the efficacy of pioglitazone as add on drug to ST in psoriatic patients especially with metabolic syndrome. With regards to safety profile the pioglitazone was found to be well tolerated and reasonably safe.

\section{CONCLUSION}

It appears from the findings of the study that pioglitazone given as add on drug provided additional benefit to psoriatic patients more so with metabolic syndrome.
Funding: No funding sources

Conflict of interest: None declared

Ethical approval: The study was approved by the Institutional Ethics Committee, PGIMS, Rohtak

\section{REFERENCES}

1. Queiro R, Tejon P, Alonso S, Coto P. Age at disease onset: a key factor for understanding psoriatic disease. Rheumatology. 2014;53(7):1178-85.

2. Boehncke WH. Etiology and pathogenesis of psoriasis. Rheum Dis Clin N Am. 2015;41(4):665-75.

3. Harden JL, Krueger JG, Bowcock AM. The immunogenetics of psoriasis: a comprehensive review. J Autoimmun. 2015;64:66-73.

4. Oliveira M, Rocha B, Duarte GV. Psoriasis: classical and emerging comorbidities. Anais Brasileiros de Dermatologia. 2015;90(1):9-20.

5. Parisi R, Rutter MK, Lunt M. Psoriasis and the risk of major cardiovascular events: cohort study using the Clinical Practice Research Datalink. J Invest Dermatol. 2015;135(9):2189-97.

6. Menter A, Korman NJ, Elmets CA, Feldman SR, Gelfand JM, Gordon KB, et al. Guidelines of care for the management of psoriasis and psoriatic arthritis: section 6. Guidelines of care for the treatment of psoriasis and psoriatic arthritis: case-based presentations and evidence-based conclusions. J Am Acad Dermatol. 2011;65(1):137-74.

7. Bongartz T, Coras B, Vogt T, Scholmerich J, Ladner MU. Treatment of active psoriatic arthritis with the PPAR gamma ligand pioglitazone: an open-label pilot study. Rheumatology. 2005;44(1):126-9.

8. Liu Y, Yang F, Ma W, Sun Q. Metformin inhibits proliferation and proinflammatory cytokines of human keratinocytes in vitro via mTOR-signaling pathway. Pharm Biol. 2016;54(7):1173-8.

9. Badri AMR, Azar ST. Effect of glucagon-like peptide-1 receptor agonists in patients with psoriasis. Ther Adv Endocrinol Metab. 2014;5(2):34-8.

10. Komiya E, Hatano R, Otsuka H, Itoh T, Yamazaki H, Yamada T, et al. A possible role for CD26/DPPIV enzyme activity in the regulation of psoriatic pruritus. J Dermatol Sci. 2017;86(3):212-21.

11. Rajagopalan $\mathrm{R}$, Iyer $\mathrm{S}$, Khan $\mathrm{M}$. Effect of pioglitazone on metabolic syndrome risk factors: results of double-blind, multicenter, randomized clinical trials. Curr Med Res Opin. 2005;21(1):16372.

12. Shafiq N, Malhotra S, Pandhi P, Gupta M, Kumar B, Sandhu K. Pilot trial: pioglitazone versus placebo in patients with plaque psoriasis (the P6). Int $\mathrm{J}$ Dermatol. 2005;44(4):328-33.

13. Hafez VG, Bosseila M, Abdel MR, Shaker OG, Kamal M, Kareem HS. Clinical effects of 'pioglitazone', an insulin sensitizing drug, on psoriasis vulgaris and its co-morbidities, a double blinded randomized controlled trial 1. J Dermatolog Treat. 2015;26(3):208-14. 
14. Enas E, Mohan V, Deepa M, Farooq S, Pazhoor S, Chennikkara $H$. The metabolic syndrome and dyslipidemia among Asian Indians: a population with high rates of diabetes and premature coronary artery disease. J Cardiometab Syndr. 2007;2(4):267-75.

15. Ashcroft DM, Wan AL, Williams HC, Griffiths CE. Clinical measures of disease severity and outcome in psoriasis: a critical appraisal of their quality. $\mathrm{Br} \mathrm{J}$ Dermatol. 1999;141(2):185-91.

16. Finlay AY, Khan GK. Dermatology Life Quality Index (DLQI) - a simple practical measure for routine clinical use. Clin Exp Dermatol. 1994;19(3):210-6.

17. World Health Organization (WHO) - Uppsala Monitoring Centre (UMC). Sweden: WHO-UMC Causality Assessment Scale; 2018. Available at: http://www.who.int/medicines/areas/quality_safety/sa fety_efficacy/WHO causality_assess. Accessed on 21 May 2019.
18. Lajevardi V, Hallaji Z, Daklan S, Abedini R, Goodari A, Abdolreza M. The efficacy of methotrexate plus pioglitazone vs. methotrexate alone in the management of patients with plaque-type psoriasis: a single-blinded randomized controlled trial. Int $\mathbf{J}$ Dermatol. 2015;54(1):95-101.

19. Mittal R, Malhotra S, Pandhi P, Kaur I, Dogra S. Efficacy and safety of combination acitretin and pioglitazone therapy in patients with moderate to severe chronic plaque-type psoriasis: A randomized, double-blind, placebo-controlled clinical trial. Arch Dermatol. 2009;145(4):387-93.

Cite this article as: Gupta MC, Nayak K, Aggarwal $\mathrm{K}$. A comparison of efficacy and safety with add on therapy of pioglitazone in adult patients of psoriasis with and without metabolic syndrome. Int J Basic Clin Pharmacol 2020;9:943-50. 